\title{
The "Principle of Autonomy" in Contract under the Civil Code of Ethiopian: Is It an Absolute Principle?
}

\author{
Melese Wondmagegnehu Belete \\ College of Law, DebreBerhan University, DebreBerhan, Ethiopia \\ Email: melewon87@gma il.com
}

How to cite this paper: Belete, M. W. (2019). The "Principle of Autonomy" in Contract under the Civil Code of Ethiopian: Is It an Absolute Principle? Beijing Law Review, 10, 795-805. https://doi.org/10.4236/blr.2019.104043

Received: May 29, 2019

Accepted: August 16, 2019

Published: August 19, 2019

Copyright ( 2019 by author(s) and Scientific Research Publishing Inc. This work is licensed under the Creative Commons Attribution International License (CC BY 4.0).

http://creativecommons.org/licenses/by/4.0/

Open Access

\begin{abstract}
Many legal systems consider the role of contract law as enforcing the agreement of the parties. The conception of autonomy or freedom of contract during the classical period of contract law suggests that the law should enforce any agreement that was "freely made" between the parties provided that it has no adverse effect on others. The contemporary trend (after 1980 G.C), inspired by the concern for fairness and justice, challenges the classical notion of autonomy of contract. While contract law emphasizes the autonomy of the parties to choose their own terms, there are some sets of restrictions, i.e. mandatory rules. These are the "rules of the game" which the parties have not chosen, and most of which are not within the powers of the parties to disregard or waive by agreement. The autonomy of contract is among the founding principles of the concept of "contract" under the Civil Code of Ethiopia (CCE). This paper examined the scope of the principle of autonomy as adopted under Book IV Title XII of the Civil Code of Ethiopia. To this end, as a doctrinal research, qualitative research method is applied to explore and understand the principle of autonomy under the Ethiopian law of contract.
\end{abstract}

Keywords

Autonomy, Freedom of Contract, Restrictions, Civil Code of Ethiopia

\section{Introduction}

From an economic perspective, contract law facilitates-at times even enables-many more forms of mutually beneficial exchanges between strangers that may be too risky without legal facilitation (Dagan, 2013). Since the society's wealth is made up of the total wealth of its members, even a simple kind of ex- 
change can improve social wealth. The underlining idea is that where two parties autonomously agree on a contract involving exchange of goods or services for money, each of the parties will be better off with the thing that they got (goods, services, or money) out of the exchange (Atiyah \& Smith, 2006). The contracting parties thus will be in a better position than they were before as a result of the transaction they undertake.

Many legal systems consider the role of contract law as enforcing the agreement of the parties. The conception of autonomy or freedom of contract during the classical period of contract law (1770-1870 G.C.) suggests that the law should enforce any agreement that was "freely made" between the parties provided that it has no adverse effect on others (Atiyah \& Smith, 2006). In furtherance of this notion, the libertarians consider the individual as the best judge of his or her own interest and consider that what was freely agreed is by definition, fair (Cserne, 2008).

According to the libertarians, individuals should be free to pursue their own self-interest but they recognize that in some cases the market may not operate efficiently (Atiyah \& Smith, 2006). For example, in cases where there is some kind of monopoly or where one party does not fully understand the contract, the law may need to intervene. According to the principle of autonomy of contract, it is assumed that everyone is free to choose which contract he or she entered into and the terms on which they wish to do so (Craswell, 1996).

Some writers go further and argue that it is no longer adequate to describe the law of contract as primarily concerned with supporting voluntary exchange in the market and correcting occasional abuses or market failures (Craswell, 1996). In their view, another transformation has taken place and the modern law's prime concern is with controlling domination and promoting fair exchange and co-operation (Craswell, 1996). The contemporary trend is towards compromising between the high adherence to the principle of autonomy and the need for limitations in freedom of contract (Kuflik, 1984).

The purpose of this paper is to examine the principle of autonomy in contract as incorporated under Book IV Title XII of the Civil Code of Ethiopia (CCE). A further explanation will be in place concerning the scope of the principle. Some of the relevant mandatory rules of the Civil Code will be analyzed in line with the justifications for limitations of autonomy in contract. With the view to exemplify the application of the rules on paper in the reality, as instrument of intervention in the autonomy of contract, the paper will examine the relevant part of the reasoning followed by the Federal Supreme Court Cassation Bench in some pertinent cases.

\section{The Principle of Autonomy in Contract: Is It Absolute or Relative?}

Autonomy is understood as the condition of being self-directed of having authority over one's choices and actions. A self-directed individual is one who sets 
goals for his life, goals that he has selected from a range of options and that he can hope to achieve as a result of his own action (Oshana, 2002). Such goals are formulated according to values, desires, and convictions that have been developed in an uncoerced fashion (Oshana, 2002). In other words, autonomy is understood as an individual's ability to make meaningful choices about one's life. An autonomous person is in control of his choices, his actions, and his will. The assumption here is that an autonomous individual has the knowledge of the circumstances and of the effective forces that are operative in these circumstances (Oshana, 2002).

The principle of autonomy considers contracts as tools for realizing individual self-determination by means of voluntarily entering legally binding agreements (Gutmann, 2013). This means that parties are free to enter or not to enter into agreements. Contract law maximizes individual autonomy by enabling individuals to undertake obligations to one another, thereby providing alternatives, without fear of breach of promises (Kraus, 2006). In general, the principle of autonomy in contract is the constitutive element of an individual's freedom to make any contractual transaction and be entitled to the enforcement of the rights and duties in such transaction.

The principle of autonomy in contract emerged with the emergence of the will theory, which was developed as a result of various juristic and philosophical thoughts in the $17^{\text {th }}$ and $18^{\text {th }} \mathrm{C}$. The will theory holds that an individual must have the freedom to undertake obligations by contract in his own deal when he desires, on conditions he thinks fit, to discuss and negotiate freely these conditions and the effects and extinction of the obligation with the other contracting party as of right (Kennedy, 1998).

The idea of autonomy/liberty of contract was favored by the laissez-fair economic view, which equalizing it with economic liberty, considered every restriction up on the will of the individual as unnecessary and tampering economic activities (Atiyah \& Smith, 2006). The will theory considers the will of the individual as the primary source of obligation on which one may not impose restrictions and the only acceptable restrictions, if any, are those made by the individual himself (Cserne, 2008). This very liberal approach tends to argue that people should have the right to choose, even, self-harming actions.

However, under the contemporary period, the will theory appeared untenable. Valuing autonomy too much may imply the total absence of restrictions, which in turn may affect the interest of the individuals concerned as well as the society in general. Parties may not provide terms for every possible incident of their transaction. In such cases, the law supplements their transaction with its own rules. Hence, it is difficult to say that the parties have been free to regulate their own transaction and some restrictions are indispensable. The more the restrictions are imposed cautiously, the better the commercial transaction would be.

\section{Limitations on Autonomy of Contract}

While contract law emphasizes the autonomy of the parties to choose their own 
terms, there are some sets of restrictions: i.e. mandatory rules. These are the "rules of the game" which the parties have not chosen, and most of which are not within the powers of the parties to disregard or waive by agreement (Bix, 2007). These kinds of rules are mostly showing the limitations of autonomy of contract, that there are terms, consequently the whole agreement, that the law will not enforce, even though the parties have consented to them (Bix, 2007).

The limitations on autonomy of contract are, in one or another way, interferes with a person's liberty of action justified by reasons referring exclusively to the welfare, good, happiness, needs, interests, or values of the person being misinformed, deceived, coerced or else (Oshana, 2002). The interference is either by preventing the person from doing whatever he has decided to do, or by interfering with the way in which he reaches his decision. Arguments in favor of limitations in contract are based on the idea that not only legal norms matter, rather, social norms do, and should, regulate which business practices are considered fair and socially acceptable (Oshana, 2002).

The limitations towards the autonomy of contracting parties can be observed in two different forms. First, it may be found in contract law, formulated in general terms and applicable to every individual case uniformly (Cserne, 2008). Second, on the other hand, there are several "genuine" contract law doctrines which are usually formulated as vague standards, leaving for the judiciary a relatively wide discretionary power (Cserne, 2008). For instance, it is for the judge to determine in individual cases whether a certain contract (provision) is "unconscionable", "immoral" or "grossly unfair".

There might be other values competing with autonomy (freedom), and note very thing valuable is a sort of freedom. Therefore, if we want to limit autonomy or freedom of choice in certain situations, it is better to say that in a given case there are good reasons for preferring some other value (e.g., welfare, security, etc.) to autonomy (Cserne, 2008).

As it has been mentioned in this paper earlier, one of the reasons for restrictions in contract is to protect harm caused to the individual by conditions beyond his control. Thus, if an intervention through mandatory rules is capable of creating benefits for the individual whose autonomy of choice it restricts, then there is a prima facie case for intervention on efficiency grounds (Oshana, 2002).

The economic reasons for intervention through mandatory rules can be generally of two types: contracting failures and market failures (Cserne, 2008). Contracting failures can be due to either the case of systematic cognitive failures or insufficient cognitive capacities or the case of constrained choice (due to the circumstances of necessity, coercion, duress, or impossibility) (Cserne, 2008). According to Cserne, market failures may be caused by insufficient outside opportunities, due to:

.... 1) externalities that lead to the unenforceability of contracts, 2) imperfect information which addressed by the doctrine of fraud, failure to disclose, or mistake, and 3) structural or situational monopoly which leads to the lack of competition, which is addressed by doctrines such as necessity, unconscionabil- 
ity, and lesion... (Cserne, 2008).

Generally, the rules that limits autonomy of contract are justified if the subject's conduct is not voluntary for incapability of making choices, lack of substantial freedom from controlling influences such as coercion, duress, or manipulation, or absence of substantial freedom from information defects, such as ignorance of the nature of one's conduct or its foreseeable consequences.

\section{Analysis of the Principle of Autonomy as Incorporated under Title XII of the CCE}

\subsection{Autonomy of Contract: The Guiding Principle}

The principle of autonomy is at the heart of every contractual relation. Such individual autonomy is expressed through knowledge about the obligation that someone is going to carry out and the benefit she or he is going to get or lose and consent to such obligation or benefit; i.e. an individual can determine his own fate (freedom of contract). The libertarian considers the individual as the best judge of his or her own interest and consider that what was freely agreed is by definition, fair (Cserne, 2008).

The autonomy of contract is among the founding principles of the concept of "contract" under the Civil Codeof Ethiopia (CCE) (The Civil Code of Ethiopia, 1960). The definitional provision of title XII of the Civil Code of Ethiopia incorporates the principle of autonomy in the sense that a person can decide to agree or not only if she or he clearly knows what rights and obligation are to be created, varied, or extinguish (The Civil Code of Ethiopia, Art. 1675, 1960). In other words, the parties to a contract are autonomous to define their obligations or undertakings and to agree to be bound thereby.

Autonomy of contract is relevant in all the processes from the making to the extinction of contract. To begin with, the principle of autonomy is relevant to the negotiation or bargaining process through offer and acceptance (The Civil Code of Ethiopia, Arts. 1679-1981, 1960). The consent of the parties to enter into a transaction is necessary. It is also at this stage that the terms and conditions of the contract are agreed.

The principle of autonomy is also inherent in the determination of the parties' right in finalizing their agreement in whatever form they prefer as long as they agree to the substance (The Civil Code of Ethiopia, Art. 1719/1, 1960). The parties are also autonomous in defining the object of their contract subject to the prohibitory rules of the law (The Civil Code of Ethiopia, Arts. 1711, 1731/2, 1960). In this regard, the case between Zemzem PLC andIllubabor Zone education bureau is worthwhile (FDRE Supreme Court Cassation Decision 1998, Cassation F. No. 16896). In the case mentioned, the parties have agreed that in case of any dispute any one of the parties may demand settlement either by court or arbitration. The cassation division criticized the lower courts' decision for their failure to recognize the autonomy of the contractants. The cassation court, though its interpretation of the dispute resolution clause is susceptible to criti- 
cism, recognized the autonomy of the contracting parties to determine the terms of their contract by virtue of Art. 1711 of the CCE.

Moreover, the principle of autonomy is relevant in relation to the parties' freedom to regulate the effects of the performance or non-performance of their contract. For instance, the parties to a contract may set a penalty clause in case one of them is in default to perform.

\subsection{Mandatory Rules as Means of Restrictions}

Mandatory provisions are those provisions that should be necessarily observed by the contracting parties when they make a contract (The Civil Code of Ethiopia, Arts. 1710-1731/3, 1960). The contractants cannot contract away the mandatory rules under the guise of autonomy of contract. The wise appreciation of mandatory rules as envisaged under the CCE is, in the writer's opinion, best achieved by investigating the reasons behind their restrictive purposes. Though there could be other reasons, public policy, contractual fairness, and security of transaction are the most important ones (Marella, 2006). Here, the phrase 'public policy' employed as justification for restrictions of autonomy needs explanation; what it mean? and how a certain contract could be said as contrary to public policy?

Though we could not have exact definition, 'public policy' means in general terms "... the protection and promotion of public welfare, including public health and morality ..." (American Jurisprudence, 532, 1964). An agreement is against public policy if it is injurious to the interest of the public, contravenes some established interest of the society, violates some public statute etc. (American Jurisprudence, 1964). There is no provision in title XII of the CCE which clearly spelt out the phrase 'public policy'. It is only by construing or interpreting rules found in the various areas of the law as a whole or non-legal (social, cultural, political) reality that we could try to find out whether a certain contract is against public policy.

To begin with the formation of contract, an agreement will not be considered as entered autonomously if it is affected by vices of consent and state of incapacity (The Civil Code of Ethiopia, Art. 1678/a, 1960). This requirement is necessitated by the interest of the public and aimed at protecting certain members of the society (minors, insane persons) which it considers are vulnerable to unregulated economic exploitation through contracts. The law potentially denies an agreement of legal enforcement by giving such party suffering from a defect in consent or incapacity the option to invalidate (The Civil Code of Ethiopia, Arts. 1808/1, 1810/1, 1811, 1960).

According to Art. 1711 of CCE, the contracting parties have a relative autonomy to determine the subject matter of their contract. The autonomy is relative because there is a restriction that requires the object to be sufficiently defined, possible, and lawful (The Civil Code of Ethiopia, Art. 1678/b, 1960). Object is deemed as not sufficiently defined when it cannot be ascertained from the terms of the contract itself, by rules of interpretation, or by the application of the sup- 
plementary rules of the law (The Civil Code of Ethiopia, Art. 1695/3, 1960), custom, and good faith (Krzeczunowich, 1983). Finding out what the parties agreed on would be unnecessary wastage of time and energy for courts. In other words, a not clearly defined subject matter of a contract would hamper the administration of justice by creating congestion of cases in courts. This is in the interest of the public, which the law intends to prevent (The Civil Code of Ethiopia, Art. 1714, 1960).

It is plain for anyone that what chaotic situations may result if people are let into any contract whose obligation relates to a thing or a fact which is impossible and if the law is ready to recognize such contracts. In cognizant of this, the law has come up with the requirement of possibility thereby restrict the autonomy of contract (The Civil Code of Ethiopia, Arts. 1678/b and 1715, 1960). In this respect, the case between AtoBekele Deboch and W/roAzalech Desalegnet al. is worth mentioning (FDRE Supreme Court Decision, 2000). For our purpose, let us focus on the pertinent part of the reasoning by the Cassation Bench. The case was concerned with a contract relating to sale of a factory and brought before the Cassation Bench of the Federal Supreme Court on the issue whether the contract should be invalidated or not. The argument of the appellant was that the factory had been mortgaged by a bank prior to the sale contract and this fact can be ascertained from the litigation held in lower courts. Accordingly, the Cassation Bench reasoned out that the sale contract is concluded with an object, which is impossible to be performed. Thus, the Cassation Bench reversed the decision of Oromia Supreme Court by arguing that according to Art. 1715 of the CCE, the object of the contract is impossible of performance.

At the extinction stage of contract, the autonomy restriction can be illustrated by a mandatory rule, which prohibits set-off when the obligation is owing to the state or municipality (The Civil Code of Ethiopia, Art. 1833/b, 1960). One can imagine how difficult it would be to realize if this is allowed.

As mentioned hereinabove, contractual fairness is the other reason behind the mandatory rules that are provided as a means of restricting autonomy of contract. One of the contracting parties should not benefit unfairly at the expense of the other and the interest of the economically weaker party should not be unfairly subordinated to the interest of economically powerful party.

To this effect, the CCE has given emphasis to the requirement of consent sustainable at law (The Civil Code of Ethiopia, Art. 1678/a, 1960) thereby aimed at protecting the party who may be subjected to dishonest dealings and cheatings. The law tries to balance or correct the unfair superior position taken by one of the parties at the expense of the other who is at a disadvantageous position due to the vices of consent (The Civil Code of Ethiopia, Arts. 1808-1810, 1960). The right to invalidate a contract, which is affected by the defects in consent, is a right which cannot be set aside contractually (limited autonomy) and exists irrespective of the agreement of the parties.

The law has also potentially limited the autonomy of the party who draft adhesive contract by interpreting the contract in favour of the other party (The 
Civil Code of Ethiopia, Art. 1738/2, 1960). The rationale behind is that in adhesive contract the party who does not prepare or participate in setting the terms and conditions of the contract has a very narrow scope of autonomy and is at the inferior position or with no opportunity to bargain over the contents of the contract than accepting them as provided by the other (Krzeczunowich, 1983).

As it has been mentioned, the parties have autonomy to regulate the effect of the non-performance of contract. According to Art. 1895 of the CCE, the parties' autonomy in fixing penalty for default in performance is subjected to courts' approval because what the court checks are whether the particular contractual sanction agreed between the parties is justified. In other words, it is measured by the court whether it is fair under the circumstances to compel the defaulting party to pay the penalty according to the agreement.

Commercial transactions are effected mainly through contracts. To ensure security of business transaction, the law provides some mandatory rules as to form which it thinks are so indispensable for the proper and ordered conduct of business. It is mainly the need to secure business transaction that motivates the legislature to lay down the formal requirements for some types of contracts (The Civil Code of Ethiopia, Arts. 1719-1730, 1960). Art. 1719/2 of the CCE introduces formal restriction from which deviation is not allowed.

The contracting parties can autonomously fix penalties in case one of the parties fails to discharge his obligation. If dispute arises to invalidate a contract as a whole due to the invalidation of penalties prescribed in it, courts would confirm the validity of the contract irrespective of a contrary agreement (The Civil Code of Ethiopia, Art. 1894/2, 1960). This is because enforcing the contract is economically better than invalidating solely for the reason that penalties prescribed in it are invalidated.

\subsection{The Restrictive Rules as Promoting Autonomy in Contract}

The contemporary idea is that the freedom of choice of an individual may, or even should, be restricted in the present if this increases his future freedom largely (Cserne, 2008). Future freedom of choice is a component of the welfare of persons (Cserne, 2008).

Although Art. 1738 of CCE imposes restriction on one of the parties to the contract by interpreting its terms against him, whether he agrees to it or not, it is a restriction imposed to ensure autonomy of contract when viewed in light of the interest of the party who did not have the chance to negotiate the terms of the contract.

The mandatory rules prevent undue interference with the autonomy of the parties to make their contract and have legally enforced. For instance, Arts. 1714/2 of CCE on interpretation safeguards autonomy of contract by confining the court to enforce the terms and conditions of a contract as the parties mean them to be when they are clear. 


\section{Summary}

Generally, the principle of autonomy, of course, is the guiding principle adopted by the Ethiopian Civil Code. The parties to a contract are autonomous to define their obligations or undertakings and to agree to be bound thereby. Under the Ethiopian Civil Code, autonomy of contract is relevant in all the processes from the making to the extinction of contract.

However, such autonomy of contract has limitations which cannot be disregarded by the contracting parties under the guise of autonomy. These limitations are provided by the Civil Code as mandatory rules for which the parties need to be obeyed. Moreover, the mandatory rules are not crafted only to restrict the autonomy of contracting parties; but also serve as to prevent undue interference of the court with the autonomy of the parties to make their contract and have legally enforced.

\section{Findings}

The analysis of title XII of the Ethiopian Civil Code hereinabove revealed that the principle of autonomy recognized as a guiding principle in the law of contract. The freedom of contract is laid down by the definitional provision (Art. 1675 of ECC) in the sense that a person can decide to agree or not only if she or he clearly knows what rights and obligation are to be created, varied, or extinguished. In other words, the parties to a contract are autonomous to define their obligations or undertakings and to agree to be bound thereby (Art. 1711).

The principle of autonomy in contract is also recognized by court decisions. This can be inferred from the Federal Supreme Court Cassation Bench decision on the case between Zemzem PLC and Illubabor Zone education bureau. The Cassation bench has reversed the decision of Oromia Supreme Court arguing in favour of the parties' autonomy to contract (Cassation F.No. 16896). The reasoning of the cassation bench has also reiterated the provision of the Civil Code that provides as a valid contract is a law between the parties (Cassation F. No. 16896).

Nevertheless, the principle of autonomy in contract under the Ethiopian Civil Code is not absolute. The Civil Code has introduced limitations on the principle of autonomy in terms of mandatory provisions that should be necessarily observed by the contracting parties when they make a contract (The Civil Code of Ethiopia, Arts. 1710-1731/3, 1960). The mandatory provisions shall not be overlooked by the contracting parties during not only the time of creating a contract, but during the stage of extinction of their relations too. The mandatory provisions, for the interest of the parties, have both the gap filling role and protective role as well. The mandatory rules prevent undue interference with the autonomy of the parties to make their contract and have legally enforced (Arts. 1714/2 of $\mathrm{CCE})$. Moreover, some restrictions are imposed to ensure autonomy of contract when viewed in light of the interest of the party who did not have the chance to negotiate the terms of the contract (Arts. 1738 of CCE). 


\section{Concluding Remarks}

The principle of autonomy emerged during the classical period of contract law (1770-1870 G.C) (Atiyah \& Smith, 2006). The underlining idea is that the function of contract law should be that of enforcing whatever private arrangements contracting parties had agreed up on (Atiyah \& Smith, 2006). So, great emphasis was on the agreement and intention of the parties, and the law was not concerned with the fairness or justice of the outcome. The judges of this period thought that it was just to enforce contractual duties strictly (Atiyah \& Smith, 2006).

The contemporary trend (after 1980 G.C), inspired by the concern for fairness and justice, challenges the classical notion of autonomy of contract (Atiyah \& Smith, 2006). The classical notion of autonomy of contract is simply concerned with the enforcement of agreements generally, including those that may be unfair or that may involve undesirable subject matters. The detrimental effects of this extremist notion necessitate the concern for the extent to which individuals are free in a meaningful sense to enter in to contract.

Title XII of the CCE is in line with the role of contracts as indispensable instrument for exchange of goods and services to money between persons. Hence, the Code in its various provisions recognizes the right of individuals to make any commercial transaction by their agreement and courts are expected to give their assistance in the enforcement of the transaction effected through contracts.

By making a few restrictions as possible on autonomy in contract, the law tries not to hamper trade through unnecessary and numerous restrictions. It is only restrictions inspired by public policy, security of trade, and contractual fairness that must be allowed to interfere with autonomy in contract. A balance must be stricken between the type and number of restrictions on the one hand and the autonomy granted to individuals to make a contract enforceable at law.

\section{Conflicts of Interest}

The author declares no conflicts of interest regarding the publication of this paper.

\section{References}

American Jurisprudence (1964). 532 (2nd ed., Vol. 17A). https://reference.findlaw.com

Atiyah, P. S., \& Smith, S. A. (2006). Atiyah's Introduction to the Law of Contract.

Bix, B. H. (2007). Consent in Contract Law. http://www.harvardlawreview.org https://doi.org/10.2139/ssrn.892783

Craswell, R. (1996). Remedies When Contracts Lack Consent: Autonomy and Institutional Competence. http://chicagounbound.uchicago.edu/journal articles

Cserne, P. (2008). Freedom of Choice and Paternalism in Contract Law: Prospects and Limits of an Economic Approach. https://ediss.sub.uni-hamburg.de/volltexte/2008/3765/pdf/edisscserne.pdf

Dagan, H. (2013). Autonomy, Pluralism, and Contract Law Theory. Law and Contempo- 
rary Problems, 76, 19.

FDRE Supreme Court Cassation Decision (1998). Zemzem PLC v. Ilubabor Zone Education Bureau, Cassation F. No. 16896.

FDRE Supreme Court Cassation Decisions (2000). Bekele Deboch v. W/ro Azalech Desalegn, Cassation F. No. 26996.

Gutmann, T. (2013). Theories of Contract and the Concept of Autonomy. http://www.uni-muenster.academia.edu

Kennedy, D. (1998). From the Will Theory to the Principle of Private Autonomy: Lon Fuller's "Consideration and Form". Columbia Law Review, 100, 94-175. https://doi.org/10.2307/1123557

Kraus, J. (2006). A Philosophical Approach to the Economic Analysis of Contract Law. Virginia Journal, 9, 9.

Krzeczunowich, G. (1983). Formation and Effects of Contracts in Ethiopian Law. Addis Ababa: Addis Ababa University Press.

Kuflik, A. (1984). The Inalienability of Autonomy. Philosophy \& Public Affairs, 13, 271-298. https://www.jstor.org/stable/2265330

Marella, M. R. (2006). The Old and the New Limits to Freedom of Contract in Europe. European Review of Contract Law, 2, 257-274. https://www.academia.edu https://doi.org/10.1515/ERCL.2006.019

Oshana, M. A. L. (2002). How Much Should We Value Autonomy? https://repository.library.georgetown.edu

The Civil Code of Ethiopia (1960). Proclamation No. 165. Addis Ababa. 